\title{
Combined Stump Pressure and Oximetry for Shunt Use During Carotid Endarterectomy
}

\author{
J. Max Findlay, Rohit Kesarwani, Michael Jacka, B. Elaine Marchak
}

\begin{abstract}
Background: Cross-clamp ischemia during carotid endarterectomy can be prevented with carotid bypass shunts in vulnerable patients identified by cerebral monitoring for ischemia. We compared transcranial cerebral oximetry (TCO) with carotid stump pressure measurements for selective shunt use. Methods: We prospectively collected data on 300 consecutive patients operated on under general anesthesia between 2009 and 2016. Shunts were inserted for a 10\% or greater drop in cerebral saturations and/or a mean stump pressure less than $40 \mathrm{mmHg}$. Results: Seventy-five patients, $25 \%$ of the study population, were shunted. The indication was a combined desaturation and stump pressure in 38 (50\% of the shunted group), desaturation alone in 11 patients (15\%), and a low stump pressure alone in 26 patients (35\%). There were no significant differences in baseline characteristics between those patients who were or were not shunted, except angiographic collateral blood supply, which was more commonly identified in patients who were not shunted. A watershed infarct occurred in just one patient with borderline TCO and stump pressure measurements in whom a shunt was not used. Conclusions: There was poor concordance between TCO and stump pressures, but using both in determining the need for shunt use almost eliminated cross-clamp ischemia in this series of 300 carotid endarterectomy patients.
\end{abstract}

RÉSUMÉ: Mesurer la pression distale au clamp et l'oxymétrie cérébrale en lien avec l'utilisation d'un tuyau de dérivation lors d'une endartériectomie carotidienne. Contexte: L'ischémie produite par l'utilisation d'un clamp lors d'une endartériectomie carotidienne peut se prévenir, chez des patients vulnérables dépistés par monitorage cérébral, au moyen de tuyaux de dérivation (shunts). Nous avons ainsi comparé les mesures de pression de l'oxymétrie cérébrale à celles de la pression distale au clamp (stump pressure) lorsque de tels tuyaux sont utilisés. Méthodes: Nous avons recueilli de façon prospective des données chez 300 patients consécutifs ayant subi, entre 2009 et 2016, une intervention sous anesthésie générale. Des tuyaux de dérivation ont ainsi été insérés lorsque survenaient une chute de saturation cérébrale en oxygène de $10 \%$ ou plus et/ou une chute de la pression distale au clamp moyenne de moins de $40 \mathrm{mmHg}$. Résultats: Soixante-quinze patients, soit $25 \%$ de notre échantillon, ont bénéficié d'une dérivation de type «shunt ». Trente-huit d'entre eux, soit environ $50 \%$ de l'échantillon, ont montré à la fois une chute de la pression distale au clamp et une désaturation cérébrale. Chez 11 patients (15\%), on a seulement observéun phénomène de désaturation alors qu'on a pu observer chez 26 d'entre eux (35\%) une baisse de la pression distale au clamp. Si l'on compare les patients ayant bénéficié d'une dérivation de type «shunt aux autres patients, nous n'avons noté, hormis le flux sanguin collatéral, plus fréquemment mesuré par angiographie chez les patients privés d'une dérivation, aucune différence importante quant à leurs caractéristiques respectives de départ. Fait à souligner, un seul patient, chez qui on avait enregistré des valeurs limites d'oxymétrie cérébrale et de pression distale au clamp et qui n'avait pas bénéficié de dérivation, a été victime d'un AVC ischémique jonctionnel (watershed infarct). Conclusions: Une faible concordance existe donc entre les mesures de pression de l'oxymétrie cérébrale et celles de la pression distale au clamp. Toutefois, le fait d'utiliser ces deux formes de monitorage pour déterminer s'il était nécessaire de procéder à une dérivation a pratiquement éliminé les cas d'ischémie produits par l'utilisation d'un clamp au sein de ce groupe de 300 patient soumis à une endartériectomie carotidienne.

Keywords: carotid endarterectomy, cerebral ischemia, cerebral monitoring

doi:10.1017/cjn.2017.210

Can J Neurol Sci. 2017; 44: 692-696

Cross-clamp ischemia during carotid endarterectomy (CEA) might be entirely preventable, either by using a carotid bypass shunt during arterial repair in all patients or by selective use of a shunt in patients who require one based on some highly reliable test or measurement of collateral blood flow and ipsilateral cerebral perfusion during cross-clamp. This test could be direct patient examination if the procedure is performed under regional anesthesia, or stump pressure measurement, transcranial cerebral oximetry (TCO), electroencephalography, somatosensory potentials, or transcranial Doppler under general anesthesia. ${ }^{1-7}$ To date, no monitoring technique or shunt practice during CEA has been proven superior to another; indeed, shunting has not yet been proven to improve outcome from $\mathrm{CEA}^{8}{ }^{8}$ Cerebral monitoring and shunt use for CEA is, currently, subject to technology available in the operating room as well as anesthetist and surgeon preference.

From the Department of Surgery (JMF, RK), University of Alberta, Alberta, Canada Department of Anaesthesia (MJ, BEM), University of Alberta, Alberta, Canada. Received February 17, 2017. Final Revisions Submitted April 5, 2017. Date of ACCEPTANCE APRIL 7, 2017.

Correspondence to: J. Max Findlay, University of Alberta Hospital - Medicine, 2D1.02 WMC, 8440112 Street, Edmonton, Alberta, Canada, T6G 2 B7.

Email: max.findlay@ahs.ca 
Our approach to avoid cross-clamp ischemia has been selective shunting based on monitoring during general anesthesia. When TCO became readily available in our operating room, we set out to prospectively compare it with traditional stump pressure measurement. We wished to compare these two relatively simple measurements with predetermined criteria for shunting, the clinical endpoint being symptomatic cross-clamp ischemia. Our hope was that strong concordance between the two would allow us to forego invasive stump pressure measurement.

\section{Methods}

All patients in the study received a general anesthetic. A balanced technique using volatile agents, muscle relaxant, and short-acting narcotics was most commonly used. Use of specific drugs and agents was not restricted by protocol and left to the discretion of the attending neuroanesthesiologist. Blood pressure (BP) was invasively monitored via radial arterial catheter. Heparin (100 U/kg body weight) was administered 3 minutes before carotid clamping. BP during carotid cross-clamping was maintained within the range of preclamp BP to $20 \%$ greater than preclamp BP. Vasoactive agents were used as required. Following carotid artery declamping, protamine was administered for heparin reversal.

Our microsurgical endarterectomy technique has already been described. ${ }^{1}$ This was a prospective study, data were collected for each individual patient at the time of surgery and with predetermined criteria for shunt insertion as described in the following section.

TCO using near-infrared spectroscopy technology was monitored continuously throughout all procedures with probes placed on either side of midline of the high forehead (Philips, Somanetics, INOVS-OXIMETER, IntelliVue G5-M1019A)."Stump pressures" were measured after cross-clamp and arteriotomy using a Bard Brener carotid bypass shunt, which has a "T" design. The proximal limb of the shunt was clamped with a mosquito clamp, the distal limb inserted into the internal carotid artery (ICA) beyond the stenosis, and the $\mathrm{T}$ arm of the shunt connected to saline filled tubing, which was attached to a pressure transducer (Figure 1).
If cerebral saturations fell $10 \%$ or more and/or the mean ICA stump pressure was found to be less than $40 \mathrm{mmHg}$, the proximal limb of the shunt was inserted into the common carotid artery proximal to the stenosis, the mosquito clamp occluding the shunt removed, and the patient was "shunted."

The TCO response to shunting and the cross-clamp time was recorded. The presence or absence of angiographic "collateral" supply to the ipsilateral hemisphere was recorded when it was clearly seen on computed tomographic angiography (CTA). This was defined as a visible either anterior or posterior communicating artery, and, in the case of the former, a visible first segment of the anterior cerebral artery as well.

The patient's neurological condition upon awakening was recorded, and a cross-clamp ischemic deficit determined by the presence of a hemispheric neurological deficit detected immediately upon awakening.

\section{Results}

Three hundred consecutive patients operated on by a single surgeon ${ }^{9}$ between 2009 and 2016 were included in this study. During this period, five patients were excluded because TCO was not available or failed during surgery, and another five patients were excluded because the shunt catheter could not be safely passed into the distal ICA (for stump pressure measurement) because of complex anatomy, namely a vascular loop, a very high exposure or resistance felt on attempted catheter placement. Our hospital Ethics Committee reviewed this study and concluded it was a quality assurance project not requiring either patient consent or Committee oversight.

The mean patient age was 69 years and $73 \%$ were men (Table 1). The indication for surgery was transient ischemic attack in $141(47 \%)$, nondisabling stroke in $75(25 \%)$, and asymptomatic stenosis in $84(28 \%)$. The degree of stenosis as reported by the neuroradiologist on CTA was $50 \%$ to $69 \%$ in $27(9 \%), 70 \%$ to $80 \%$ in $156(52 \%), 81 \%$ to $90 \%$ in $78(26 \%)$, and $91 \%$ to $99 \%$ in $39(13 \%)$.

The mean baseline cerebral oxygen saturation was $73 \%$, and there was either no change or an increase in saturations after cross-

\section{Table 1 : Patient characteristics}

\begin{tabular}{|c|c|c|c|c|}
\hline & Total & Shunted & Not shunted & \\
\hline Number of patients & 300 & 75 & 225 & \\
\hline Age & $69.5 \pm 9.1$ & $72.0 \pm 7.7$ & $69.0 \pm 9.4$ & $\mathrm{p}>0.05^{*}$ \\
\hline Gender ( $\%$ men $)$ & $219(73)$ & 66 & 76 & $\mathrm{p}>0.05^{*}$ \\
\hline Side of surgery (\% right) & $159(53)$ & 56 & 52 & \\
\hline Presentation $(\%)$ & & & & $\mathrm{p}>0.05^{*}$ \\
\hline TIA & $141(47)$ & $41(55)$ & $114(51)$ & \\
\hline Stroke & $75(25)$ & $22(29)$ & $62(27)$ & \\
\hline Asymptomatic & $84(28)$ & $12(16)$ & $49(22)$ & \\
\hline Mean stenosis (\%) & $80.0 \pm 11.7$ & $82.6 \pm 10.4$ & $79.3 \pm 12.0$ & $\mathrm{p}>0.05^{*}$ \\
\hline Presence of "collateral" $(\%)(n=160)$ & $146(91)$ & $29(73)$ & $116(97)$ & $\mathrm{p}<0.005 \dagger$ \\
\hline Mean baseline $\mathrm{SO}_{2}$ & $73 \pm 8$ & $73 \pm 8$ & $73 \pm 8$ & $\mathrm{p}>0.05^{*}$ \\
\hline
\end{tabular}

*Student $t$ test.

$\dagger$ Fisher exact test. 
Table 2: Transcerebral oximetry $\left(\mathrm{rSO}_{2}\right)$

\begin{tabular}{l|c}
\hline Mean baseline $(\mathbf{n}=\mathbf{3 0 0})$ & $\mathbf{7 3 \%}$ mean baseline oxygen saturation \\
\hline No change or increase (\%) & $89(30)$ \\
\hline Drop of $<10 \%(\%)$ & $162(54)$ \\
\hline Drop of $10 \%-14 \%(\%)$ & $28(9)$ \\
\hline Drop of $15 \%-20 \%(\%)$ & $12(4)$ \\
\hline Drop of $>20 \%(\%)$ & $9(3)$ \\
\hline "Dangerous drop" $>10 \%(\%)$ & $28+12+9=49(16)$ \\
\hline
\end{tabular}

clamp in 89 patients $(30 \%)$. A drop of less than $5 \%$ occurred in 90 patients (30\%), $6 \%$ to $9 \%$ in $72(24 \%)$, a drop of $10 \%$ to $14 \%$ in $28(9 \%)$, a drop of $15 \%$ to $19 \%$ in $12(4 \%)$, and a drop of $20 \%$ or greater in nine $(3 \%)$. A total of 49 patients had what we classified a potentially dangerous desaturation of $10 \%$ or greater $(16 \%)$ (Table 2).

The mean stump pressure (in $\mathrm{mmHg}$ ) was 50 or greater in 156 patients (52\%), 40 to 49 in $80(27 \%), 30$ to 39 in $36(12 \%), 20$ to 29 in $23(8 \%)$, and less than 20 in five patients (2\%). A total of 64 patients $(21 \%)$ had what we classified a potentially dangerous stump pressure of less than $40 \mathrm{mmHg}$ (Table 3 ).

Seventy-five patients, $25 \%$ of the study population, were shunted (Table 4). The indication was a combined low saturation and stump pressure in 38 (50\% of the shunted group). Desaturation alone (i.e. stump pressure 40 or greater) prompted shunt insertion in 11 patients (15\% of the shunted group), and a low stump pressure alone (i.e. no concomitant significant change in saturations) led to shunt insertion in 26 patients (35\% of the shunted group). As shown in Table 1, there were no significant differences in baseline characteristics between those patients who were shunted versus those who were not, with the exception of collateral blood supply. In the 160 patients in whom the presence or absence of collateral supply could be clearly seen on CTA, $97 \%$ not shunted had collateral flow versus $77 \%$ of those shunted $(\mathrm{p}<0.005)$.

Of the 49 patients who were shunted on the basis of cerebral oxygen desaturation, all but seven recovered to saturation within $10 \%$ of their baseline following shunting.

The mean cross-clamp time in the whole study population was 25 minutes, 25 minutes in the patients not shunted, and 23 minutes in those that were shunted.

During the study period, there were two patients who awoke with hemispheric neurological deficits, and both demonstrated watershed infarcts on postoperative imaging. The first was a patient excluded from the study whose TCO showed a $20 \%$ desaturation after cross-clamp, but a shunt could not be

Table 3: Mean ICA stump pressures ( $\mathrm{mmHg}$ )

\begin{tabular}{l|c}
\hline$\geq \mathbf{5 0}$ & $\mathbf{n = 1 5 6 ( \mathbf { 5 2 } \% )}$ \\
\hline $40-49(\%)$ & $80(27)$ \\
\hline $30-39(\%)$ & $36(12)$ \\
\hline $20-29(\%)$ & $23(8)$ \\
\hline$<20(\%)$ & $5(2)$ \\
\hline "Dangerous pressure" (\%) & $36+23+5=64(21)$ \\
\hline
\end{tabular}

Table 4: Shunted patients: $n=75(25 \%)$

\begin{tabular}{l|c}
\hline Combined low $\mathrm{SO}_{2}+$ low stump pressure & $\mathbf{n}=\mathbf{3 8}(\mathbf{5 0 \%})$ \\
\hline Low $\mathrm{SO}_{2}$ alone $(\%)$ & $11(15)$ \\
\hline Low stump pressure alone $(\%)$ & $26(35)$ \\
\hline
\end{tabular}

inserted for either stump pressure measurement or shunting due to the high and distal stenosis and repair. This patient awoke slowly with a profound left-sided weakness and neglect. CTA showed the arterial repair patent but subsequent computed tomography scanning revealed a right frontoparietal watershed infarct. The patient was ambulatory but had permanent and disabling hemiparesis at 1-year follow up. The second was a patient included in the study whose fall in saturation was $15 \%$, but then recovered to a $10 \%$ desaturation from baseline during cross-clamp, and whose stump pressure was $40 \mathrm{mmHg}$. His postoperative motor and speech deficit recovered to baseline (he had suffered a minor stroke) within 24 hours, but he had a new 1.5-cm subcortical parieto-occipital infarct on a computed tomography scan done before discharge home. No other patients in this series that awoke with unexpected global or focal hemispheric deficits.

\section{DiscuSSION}

Cerebral ischemia as the result of carotid cross-clamping during CEA is a less common cause of stroke because most persons have sufficient collateral flow to sustain their cerebral hemisphere for as long as it takes to complete the procedure and restore flow. ${ }^{10}$ When cross-clamp ischemia does occur, it is immediately apparent. Patients undergoing surgery under regional anesthesia become less responsive or agitated and develop contralateral weakness, which reverses with declamping. When significant cross-clamp ischemia occurs during general anesthesia, patients awaken slowly and demonstrate global contralateral weakness or paralysis, hemineglect, and often ipsilateral gaze paresis. Watershed distribution infarcts become apparent on follow-up brain imaging.

A more common cause of stroke complicating CEA is thromboembolism or delayed postoperative carotid occlusion at the repair site, often related to a technical flaw in the repair. ${ }^{11,12}$ This type of postoperative stroke differs from cross-clamp ischemia by having an onset hours after the procedure. ${ }^{12-14}$ Much of the literature on monitoring and shunt use examines a delayed and often 30-day stroke risk $^{8}$ as an endpoint when the pertinent strokes related to cross-clamp are immediately apparent.

Arguments against routine shunt use include that it is clearly not required in a large number of patients, shunt placement is sometimes difficult (such as in patients with distal "high" carotid bifurcations or long atherosclerotic plaques) and shunt insertion itself might precipitate a stroke by causing plaque embolization, injuring the distal carotid or creating an arterial dissection. The presence of a temporary indwelling shunt makes the technical performance of CEA more demanding. For those reasons, some surgeons have a policy of never shunting, but a popular middle approach is selective shunt use based on some assessment of brain condition or hemispheric blood flow during cross-clamp. ${ }^{1,4,15,16}$

We set out to compare stump pressures with what for us when this series began was a relatively new technology for carotid 


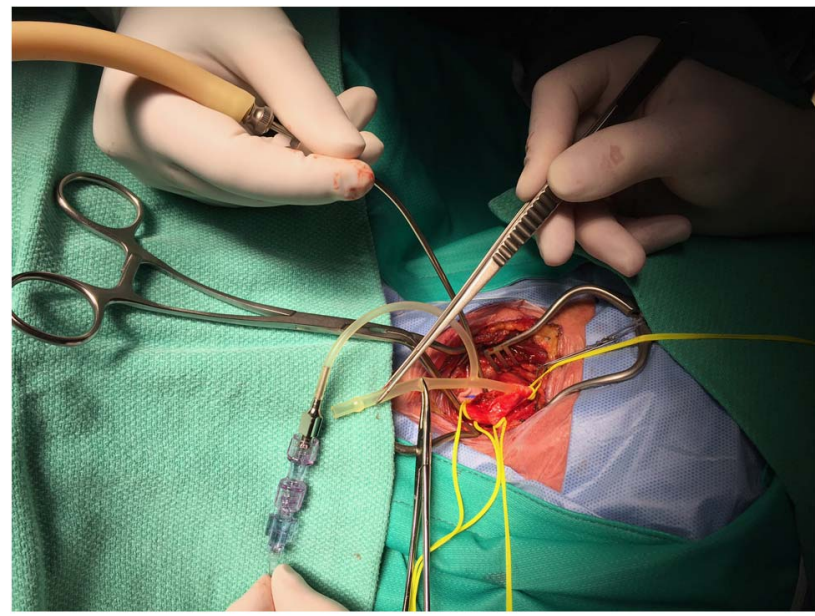

Figure 1: Method of stump pressure measurement using a Bard Brenner carotid bypass shunt (see text for details).

surgery, TCO. Simple and entirely noninvasive, we hoped TCO could replace the trouble, time, and potential danger of stump pressure measurement.

Stump pressure is the perfusion pressure transmitted around the circle of Willis and down the internal carotid beyond the crossclamp. Aside from subjective impression of the degree of "back bleeding" down the ICA after cross-clamp, stump pressures were the first actual measurement used during CEA to help guide shunt placement. ${ }^{17-19}$ A number of thresholds for stump pressure, ranging between 25 and $70 \mathrm{mmHg}$, have been proposed, below which shunting would be indicated. ${ }^{2,8,20}$ Using direct neurological examination as the "gold standard" for cerebral ischemia in patients undergoing CEA under regional anesthesia, it was found that a stump pressures less than $40 \mathrm{mmHg}$ had a sensitivity of $57 \%$ and specificity of $97 \%$ for predicting a neurological deficit. ${ }^{21}$

Transcranial cerebral oximetry with near infrared spectroscopy provides a value for regional cerebral oxygenation $\left(\mathrm{rSO}_{2}\right)$ beneath the scalp monitor, which is a composite of both arterial and venous oxygenation. $^{22,23}$ The signal may be contaminated by blood flow in extracranial tissues and TCO monitors placed for CEA detect frontal lobe blood flow, not necessarily reflecting middle cerebral arterial perfusion. As with stump pressure measurements, a TCO's specificity has been shown to exceed its sensitivity. ${ }^{24}$ Despite these limitations and that the cutoff point indicating definite cerebral ischemia is unclear, the simplicity of TCO makes it appealing as a cerebral perfusion monitor for CEA. ${ }^{25}$

A weakness of this study is that it could not generate sensitivity, specificity, or predictive values for TCO or stump pressure measurements because those calculations require values tested against a gold standard of cerebral ischemia. In the case of CEA, the best gold standard is the clinical status of patients being monitored under regional anesthesia, and for a number of reasons our operations were and are performed under general anesthesia. Our hope was to demonstrate that we could eliminate invasive stump pressure measurements, but we found there was not a good concordance between TCO and stump pressures, and a significant number of shunted patients had a shunt placed based on a low stump pressure alone (35\%), or desaturation alone (15\%). At the same time, a welcome finding in our study was that using this "dual monitoring" with TCO and stump pressure measurement virtually eliminated cross-clamp ischemia as a complication in a large series of CEA patients.

We did have one serious case of cross-clamp ischemia during the study period, but his local anatomy precluded shunt placement indicated by a $20 \%$ drop in ipsilateral $\mathrm{rSO}_{2}$ (stump pressure could not be measured). A second patient and one included in the study suffered a small watershed infarct with borderline values in both TCO and stump pressure (down $10 \%$ and $40 \mathrm{mmHg}$, respectively), and our decision not to use a shunt when both monitors were "borderline" was a mistake that we have learned from.

As already mentioned, there is variability in TCO and stump pressure thresholds for shunt insertion reported in the literature, and the values we chose and (and considered conservative) remain unproved. A reasonable question was whether choice of a stump pressure below $50 \mathrm{mmHg}$ as threshold would have captured the patients shunted based on TCO alone. Of the 80 patients whose stump pressure was between 40 and $49 \mathrm{mmHg}$, six were among the 11 patients were shunted because of a desaturation of greater than $10 \%$. A stump threshold of $50 \mathrm{mmHg}$ would therefore have resulted in 80 additional shunt insertions and still missed five patients with what we classified a "dangerous" cerebral desaturation. Conversely, if we had chosen a desaturation of $5 \%$ or greater as threshold for shunt insertion, we would have shunted an additional 72 patients, only 12 of whom were among the 26 patients shunted based on stump pressures alone. So adjusting to more conservative thresholds for either of the two monitoring techniques studied would have led to far greater shunt use but not the same patient population that we shunted in this study.

As stated at the outset, the ideal monitoring technique and optimal threshold for shunt is not yet known, but in our opinion the dual method described in this report appears additive, almost eliminating cross-clamp ischemia, providing a shunt can be inserted under the anatomical conditions imposed by the patient.

It is probable we shunted more patients than required. Shunt requirements when surgery is performed under regional anesthesia ranges from $10 \%$ to $20 \%$ of patients. ${ }^{26}$ Others, however, have raised the possibility that subtle neurocognitive decline following CEA (quite apart from the global hemispheric deficit evident upon awakening used as the endpoint in this analysis) might be related to cross-clamp hypoperfusion, an argument for routine shunt use. $^{27,28}$

We did find that the presence of an anatomically intact circle of Willis predicts sufficient collateral flow and a reduced probability that a shunt will be required, consistent with the findings of others. $^{29,30}$ In our experience, however, it is sometimes impossible to be certain of circle of Willis anatomy on CTA, which is known to be fully intact in only about $50 \%$ of the population. ${ }^{31}$ Our results suggest that the combination of TCO and stump pressure measurement is a highly effective way of selecting patients for shunt insertion during CEA.

\section{Disclosures}

The authors do not have anything to disclose.

\section{REFERENCES}

1. O'Kelly CJ, Butcher KS, Marchak BE, et al. Carotid revascularization: an update. Can J Neurol Sci. 2010;37:320-35.

2. Howell SJ. Carotid endarterectomy. Br J Anaesth. 2007;99: 119-31. 
3. Mortiz S, Kasprzak P, Arlt M, et al. Accuracy of cerebral monitoring in detecting cerebral ischemia during carotid endarterectomy - a comparison of transcranial Doppler sonography, near-infrared spectroscopy, stump pressure, and somatosensory evoked potentials. Anesthesiology. 2007;107:563-9.

4. AbuRahma AF, Mousa AY, Stone PA. Shunting during carotid endarterectomy. J Vasc Surg. 2011;54:1502-10.

5. Thirumula PD, Thiagarajan K, Gedela S, et al. Diagnostic accuracy of EEG changes during carotid endarterectomy in predicting perioperative strokes. J Clin Neurosci. 2016;25:1-9.

6. Nwachuku EL, Blazer JR, Yabes JG, et al. Diagnostic value of somatosensory evoked potential changes during carotid endarterectomy: a systematic review and meta-analysis. JAMA Neurology. 2015;72:73-80.

7. Radak D, Sotirovic V, Obradovic M, et al. Practical use of nearinfrared spectroscopy in carotid surgery. Angiology. 2014; 64:769-72.

8. Chongruksut W, Vaniyapong T, Rerkasem K. Routine or selective carotid artery shunting for carotid endarterectomy (and different methods of monitoring in selective shunting). (Review). Cochrane Database System Rev. 2014;6:1-38.

9. Findlay JM, Marchak EB, Pelz DM, et al. Carotid endarterectomy: a review. Can J Neurol Sci. 2004;31:22-36.

10. Kretz B, Abello N, Kazandijian C, et al. Risk index for predicting shunt in carotid endarterectomy. Ann Vasc Surg. 2014;28:1204-12.

11. Ferguson GG, Eliasziw M, Barr HW, et al. The North American Symptomatic Carotid Endarterectomy Trial: surgical results in 1415 patients. Stroke. 1999;30:1751-8.

12. Rothwell PM, Eliasziw M, Gutnikov SA, et al. Analysis of pooled data from the randomized controlled trials of endarterectomy for symptomatic carotid stenosis. Lancet. 2003;361:107-16.

13. Jacobowitz GR, Rockman CB, Lamparello PJ, et al. Causes of perioperative stroke after carotid endarterectomy: special considerations in symptomatic patients. Ann Vasc Surg. 2001; 15:19-24.

14. Sheehan MK, Baker WH, Littooy FN, et al. Timing of post carotid complications: a guide to safe discharge planning. J Vasc Surg. 2001;34:13-26.

15. Bond R, Rerkasem K, Counsell C, et al. Routine or selective carotid artery shunting for carotid endarterectomy (and different methods or monitoring in selective shunting). Cochrane Database Syst Rev. 2002;(2).

16. Rerkasem K, Rothwell PM. Systematic review of the operative risks of carotid endarterectomy for recently symptomatic stenosis in relation to the timing of surgery. Stroke. 2009;40:e564-72.
17. Crawford ES, DeBakey ME, Blaisdell FW, et al. Hemodynamic alterations in patients with cerebral arterial insufficiency before and after operation. Surgery. 1960;48:76-94.

18. Hays RJ, Levinson SA, Wylie EJ. Intraoperative measurement of carotid back pressure as a guide to operative management for carotid endarterectomy. Surgery. 1972;72:953-60.

19. Moore WS, Hall AD. Carotid artery back pressure: a test of cerebral tolerance to temporary carotid occlusion. Arch Surg. 1969;99:702-10.

20. Calligaro KD, Dougherty MJ. Correlation of carotid artery stump pressure and neurologic changes during 474 carotid endartectomies performed in awake patients. J Vasc Surg. 2005;42:684-9.

21. Hans SS, Jareunpoon O. Prospective evaluation of electroencephalography, carotid artery stump pressure, and neurologic changes during 314 consecutive carotid endarterectomies performed in awake patients. J Vasc Surg. 2007;45:511-5.

22. Waltzman HM, Kurth CD, Montenegro LM, et al. Arterial and venous contributions to near-infrared cerebral oximetry. Anesthesiology. 2009;93:947-53.

23. Owen-Reece H, Smith M, Elwell CE, et al. Near infrared spectroscopy. Br J Anaesth. 1999;82:418-26.

24. Samra SK, Dy EA, Welch K, et al. Evaluation of a cerebral oximeter as a monitor of cerebral ischemia during carotid endarterectomy. Anesthesiology. 2000;93:964-70.

25. Pennekamp GWA, Bots ML, Knappelle LJ, et al. The value of nearinfrared spectroscopy measure cerebral oximetry during carotid endarterectomy in perioperative stroke prevention. A review. Eur J Vasc Endovasc Surg. 2009;38:539-45.

26. Stoneham MD, Stamou D, Mason J. Regional anaesthesia for carotid endarterectomy. Br J Anaesth. 2015;114:372-83.

27. Mocco J, Wilson DA, Ducruet AF, et al. Elevations in preoperative monocyte count predispose to acute neurocognitive decline after carotid endarterectomy or asymptomatic carotid artery stenosis. Stroke. 2006;37:240-2.

28. Ghogawala Z, Westerveld M, Amin-Hanjani S. Cognitive outcomes after carotid revascularization: the role of cerebral emboli and hypoperfusion. Neurosurgery. 2008;62:385-95.

29. Wain RA, Veith FJ, Berkowitz BA, et al. Angiographic criteria reliably predict when carotid endarterectomy can be safely performed without a shunt. J Am Coll Surg. 1999;189:93-101.

30. AbuRahma AF, Stone PA, Mousa AY, et al. Correlation of carotid stump pressure during carotid endarterectomy and the contralateral carotid/cerebral collateral flow: results from a randomized trial. J Vasc Surg. 2010;52:809.

31. Alpers BJ, Berry RG, Paddison RM. Anatomical studies of the circle of Willis in normal brain. Arch Neurol Psychiatry. 1959;81:409-18. 